\title{
Defensiehulp in het licht van een pluraliserende politiefunctie
}

\author{
Eric Bervoets en Sander Eijgenraam*
}

De term militaire bijstand roept al gauw de associatie op met het geweldsmonopolie van de staat (Forster 2006; Timmer 2011). Wij richten ons in deze bijdrage echter op bijstand waarbij geweld veelal geen rol speelt, die minder bekend is en van meer recente datum. Namelijk de specialistische militaire bijstand door andere krijgsmachtonderdelen dan de Koninklijke Marechaussee. Denk aan het helpen van de politie met zoeken, analyseren en observatie door militairen die geen opsporingsambtenaar zijn, maar wel over forensische expertise beschikken. Daarover gaat ons onderzoek Defensiehulp (Bervoets 2017), waarin we als kernbevinding hanteren dat deze legergroene ${ }^{1}$ militaire bijstand de afgelopen jaren is toegenomen, wat overigens niet betekent dat militairen dagelijks bij de politiebureaus over de vloer komen. Een andere bevinding is dat de specialistische militaire bijstand zowel bij defensie als bij politie bureaupolitieke reacties oproept. Daarop gaan we in deze bijdrage nader in.

De centrale vraagstelling voor dit artikel is: in hoeverre kan specialistische militaire bijstand worden gezien als een voorbeeld van een pluraliserende politiefunctie (plural policing)? Wat zijn bij deze bijstandverlening bureaupolitieke gevoeligheden bij politie en krijgsmacht en welke nieuwe vragen roept het antwoord op de vorige vragen op? Met militaire bijstand bedoelen we in dit artikel: de door bestuurlijke of justitiële autoriteiten gevraagde specialistische hulp van de krijgsmacht aan de politie bij de handhaving van de openbare orde of bij strafrechtelijke handhaving van de rechtsorde in Nederland. De militaire hulpverlening in het geval van rampen wordt hier buiten beschouwing gelaten, evenals terreurbestrijding - 'bijzondere bij-

* Dr. E. Bervoets is zelfstandig criminoloog en bestuurskundige en eigenaar van Bureau Bervoets. A. Eijgenraam MSc is socioloog en nam als onderzoeker samen met Bervoets deel aan het onderzoek Defensiehulp voor het Programma Politie en Wetenschap.

1 Legergroen geeft onterecht de indruk dat het alleen gaat om militairen van de Koninklijke Landmacht. Bij de bedoelde bijstand kan het echter ook gaan om militairen van de Koninklijke Marine of de Koninklijke Luchtmacht. 
stand' in juridisch jargon. Ook bijstand in het Caribisch gebied, bijvoorbeeld het onderscheppen van drugs door de Koninklijke Marine of verleden jaar het handhaven van de openbare orde op Sint-Maarten na de tropische orkaan Irma, valt buiten onze afbakening. Het gaat hier in de woorden van de krijgsmacht zelf om 'de nationale operaties van de krijgsmacht in Nederland'. Bij militaire bijstand wordt defensiepersoneel onder gezag van een civiele autoriteit geplaatst: een burgemeester in het geval van openbare orde en een officier van justitie bij strafrechtelijke handhaving.

Het vertrekpunt van dit artikel is plural policing, ofwel een pluraliserende politiefunctie. Daarbij gaat het volgens Devroe en Terpstra om 'the rise of new non-police providers of policing services' (2015, p. 235). We definiëren deze pluralisering daarom als een maatschappelijk proces, waarbij steeds meer actoren opdoemen buiten de reguliere politieorganisatie $(\mathrm{s})^{2} \mathrm{om}$, die voorzien in specifieke politiediensten aan de samenleving en daarmee inhoud geven aan de politiefunctie. Laatstgenoemde definiëren we als de organisatie van formele sociale controle in een samenleving (Cachet 1990). Daartegenover staan meer informele vormen van sociale controle door burgers zelf. Verderop in de tekst gaan we dieper in op (voorbeelden van) plural policing en de daarmee gepaard gaande bureaupolitiek die we aantroffen in ons onderzoek. Bureaupolitiek - ons derde centrale begrip - definiëren we als belangenconflicten tussen publieke organisaties over personeel, middelen en bestaansrecht (vgl. Rosenthal e.a. 1994).

Om de vraagstelling te beantwoorden, bekijken we wat de plaats is van de 'legergroene' specialistische bijstand binnen de politiefunctie, en of het etiket pluralisering wel past bij dit soort hulpverlening aan de politie. Om tot een afgewogen beoordeling te komen, schetsen we vooraf - zeer op hoofdlijnen - enkele verschillen tussen het heden en verleden van de legergroene bijstand. En we gaan in op situaties waarin 'het schuurt' tussen politie en defensie, op zoek naar bureaupolitiek bij de inzet van specialistische militaire bijstand. We ronden deze bijdrage af met een korte samenvatting van het antwoord op de centrale vraagstelling en met nieuwe vragen. Eerst echter geven we aan wat de onderzoeksopzet was van ons onderzoek Defensiehulp en lichten we het door ons gehanteerde vertrekpunt toe.

2 We hanteren hier een meervoud, omdat in Nederland twee politieorganisaties naast elkaar bestaan: de Nationale Politie en de Koninklijke Marechaussee. 


\section{Onderzoeksopzet}

Dit artikel is gebaseerd op literatuur over de pluraliserende politiefunctie en ons eerdere onderzoek Defensiehulp (Bervoets 2017). Voor dat onderzoek werden in totaal 62 personen geïnterviewd. ${ }^{3}$ Het betrof 21 politiemensen, 27 militairen, in totaal 6 ambtenaren van het ministerie van Defensie, 3 van het ministerie van Justitie en Veiligheid en ten slotte 5 vertegenwoordigers van het bevoegd gezag (Openbaar Ministerie of burgemeester). Deze interviews gingen onder meer over ontwikkelingen van specialistische militaire bijstand aan de politie (concrete voorbeelden, beelden en de eigen visie van de geïnterviewde), alsmede over kansen en beperkingen van deze militaire bijstand. Van de 62 personen werden er 44 (tevens) geïnterviewd over één specifieke casus, zodat de verschillende ervaringen konden worden vergeleken. Er zijn uiteindelijk vijf casussen van de door ons bedoelde militaire bijstand geselecteerd, waarvan op voorhand bekend was dat die wezenlijke overlap vertonen met kernactiviteiten van de politie: zoeken, analyseren en observeren. ${ }^{4}$ Per casus werden enkele (groeps)interviews met sleutelpersonen gehouden, alsmede documentatie en literatuur verzameld om een beeld te krijgen van de casus. De casuïstiek over 'zoeken' betreft de bijstand door speciale zoekteams van de Koninklijke Landmacht, de Defensie Duikgroep en de military trackers (spoorzoekers) van het Korps Mariniers. Bij 'observeren' en 'analyseren' gaat het om de casus rond de eenheid JISTARC (Joint Intelligence Surveillance Target Acquisition Reconnaissance Commando) en het Civiel en Militair Interactie Commando (CMI Commando). Het JISTARC helpt af en toe de politie met data-analyse en heeft mensen en materieel om observaties uit te voeren op personen en objecten. Het CMI, ten slotte, heeft als taak om tijdens uitzendingen de lokale bevolking in kaart te brengen en er contact mee te maken teneinde de militaire missie positief te beïnvloeden. Hun expertise werd de afgelopen jaren ook binnen Nederland toegepast ter ondersteuning van het gebiedswerk door de politie. Op deze eenheden

3 Zie verder de verantwoording in detail in Bervoets 2017.

4 Uit onze analyse van het aantal bijstandsaanvragen, de analyse van open bronnen (waaronder kranten en vakbladen) - zie voetnoot 5 - en de interviews is gebleken dat het merendeel van de specialistische bijstand neerkomt op zoeken, analyseren en observeren (Bervoets 2017, p. 48-53). Met kernactiviteit bedoelen we geen kerntaak, maar een terugkerende activiteit binnen het politiewerk die inherent is aan de uitvoering van de politietaak. Dus een van de vaste bestanddelen van het politiewerk. 
en hun meerwaarde voor binnenlands optreden komen we verderop in dit artikel terug. ${ }^{5}$

\section{Perspectief: een pluraliserende politiefunctie}

We bekijken de door ons bedoelde militaire bijstand in het licht van de pluralisering van de politiefunctie. De afgelopen jaren gebeurde het steeds meer dat bepaalde politietaken door anderen worden ingevuld dan de reguliere politie (Devroe \& Terpstra 2015). Zo hebben gemeenten eigen buitengewone opsporingsambtenaren in dienst (boa's) om naast de politie toezicht te houden in de openbare ruimte en waar nodig bekeuringen uit te schrijven (Bervoets 2013; Bervoets \& Rovers 2016). Daarnaast hebben private beveiligers een grotere rol gekregen in de samenleving, vaker ook in de openbare ruimte (Van Steden 2007; Bervoets \& Eijgenraam 2014). Verder zien we burgers op straat lopen in een hesje om via 'do-it-yourself policing' in de buurt een oogje in het zeil te houden of ze nemen deel aan een whatsappgroep (Bervoets 2015; Bervoets e.a. 2016; Van Stokkom \& Bervoets 2017). ${ }^{6}$ Aan het rijtje van personen en organisaties die inhoud geven aan de politiefunctie in de samenleving kunnen we volgens sommigen ook bijstandverlenende militairen toevoegen (Neuteboom 2017).

Het verschijnsel 'plural policing' komt tegenwoordig in veel westerse samenlevingen voor (Loader 2000; Jones \& Newburn 2006; Crawford 2007; Terpstra e.a. 2013; Devroe 2015; O’Neill \& Fyfe 2017). Een veelgehoorde verklaring voor dit fenomeen is dat samenlevingen andere en nieuwe oplossingen zoeken voor het door burgers ervaren tekort aan handhaving en toezicht (Garland 2001; Brodeur \& Shearing 2005; Devroe 2015). Specifiek voor Nederland geldt dat de politie zich meer is gaan toeleggen op opsporing en het toezicht overlaat aan anderen of dat samen met andere - bijvoorbeeld private - partijen doet. Boven-

5 Daarnaast wilden we nog met een analyse van de aard en de aantallen bijstandsaanvragen de aard en de omvang van de bijstand in beeld krijgen. Die gegevens werden door ons opgevraagd bij het ministerie van Defensie. In aanvulling op deze registratieanalyse deden we aan de hand van een aantal zoektermen een openbronnenonderzoek. We bestudeerden krantenberichten en berichten in vakbladen van defensie en politie. De zoektermen staan in ons rapport (Bervoets 2017). Op de registratieanalyse en het openbronnenonderzoek wordt in dit artikel verder niet ingegaan.

6 Hoewel het bij het toezicht door burgers minder duidelijk is of dit hoort bij het invullen van de politiefunctie, want met politiefunctie duiden we in eerste instantie op formele sociale controle. Desalniettemin is sprake van op het politiewerk aanvullende (informele) sociale controle. 
dien werden gemeenten en burgers in het verleden uitgedaagd om zelf een actievere rol te spelen in het veiligheidsbeleid, wat ook in toenemende mate gebeurt (Terpstra 2010). Pluralisering gaat overigens niet vlekkeloos, zonder - soms felle - bureaupolitiek en ervaren concurrentie (Bervoets 2013; Bervoets \& Eijgenraam 2014; Devroe \& Terpstra 2015). De politie heeft niet graag dat anderen (delen van) de politietaak overnemen, terwijl ze die taken graag zelf zou willen of moeten uitvoeren. Verderop in het artikel gaan we dieper in op deze bureaupolitiek.

Enkele jaren geleden verscheen het rapport Politiefunctie in perspectief (Van den Berg e.a. 2012). Daaruit blijkt dat plural policing niet nieuw is in Nederland. Naast de politie en de Koninklijke Marechaussee zijn er in het Koninkrijk al sinds lange tijd diverse andere actoren die de politiefunctie gestalte geven. Denk aan bijzondere opsporingsdiensten en inspecties, die soms nog stammen uit de negentiende eeuw. Die verzorgen vaak op heel specifieke beleidsterreinen - bijvoorbeeld transport of economisch verkeer - het toezicht en de handhaving. De auteurs van het rapport stellen de 'politiefunctie' gelijk aan wat Reiner (2010) verstaat onder 'policing'. Het gaat bij die definitie niet uitsluitend om de politie als organisatie, maar ook om de politie als institutie en het bredere politiebestel met publieke en private actoren die elk (een deel van) de politietaak uitvoeren. Voor 'de politiefunctie' geldt dat deze breder is dan de taken die de politie en de Koninklijke Marechaussee uitvoeren. Hoewel de pluralisering van de politiefunctie de afgelopen jaren is toegenomen is een plurale politiefunctie - in elk geval in ons land - derhalve niet nieuw.

\section{Legergroene bijstand: drie belangrijke verschillen tussen heden en verleden}

Gebaseerd op ons onderzoek Defensiehulp, nemen wij drie opvallende verschillen waar tussen heden en verleden van de legergroene militaire bijstand (Bervoets 2017). Die verschillen zijn van belang om de bedoelde bijstand en de plaats ervan binnen de politiefunctie te kunnen beoordelen.

Wat allereerst opvalt, is dat de politie pas na de Tweede Wereldoorlog een eigen antwoord heeft op grootschalige openbareordeverstoringen. Eerst in de vorm van de 'harde bijstand' door de rijkspolitie met onder 
andere pantservoertuigen en de karabijnbrigades van enkele gemeentepolitiekorpsen. Pas sinds de ordeverstoringen van de roerige jaren zestig verscheen de Mobiele Eenheid in het straatbeeld (Fijnaut 2007). Voorheen, en dan met name voor de Tweede Wereldoorlog, was het optreden bij rellen en ordeverstoringen voornamelijk het domein van militairen. Die werden heel vaak als vangnet gebruikt voor de toenmalige politieorganisaties en vulden daarmee (een deel van) de politiefunctie in (zie het artikel van Smeets in dit themanummer, waarin uitgebreid wordt ingegaan op de achtergronden van deze situatie). Een tweede verschil gaat over de aard van de legergroene bijstand. Waar die bijstand historisch vooral bestond uit optreden bij openbareordeverstoringen, bestaat de legergroene bijstand tegenwoordig vooral uit specialistische bijstand aan de recherche. Er zijn diverse vormen van dat type bijstand, die uiteindelijk neerkomen op zoeken, observatie of analyse. Bij 'zoeken' moet onder meer worden gedacht aan de bijstand door de speciale zoekteams van de Koninklijke Landmacht en de Koninklijke Marine, die de politie geregeld helpen met onder andere huiszoekingen. Deze 'advanced search teams' zijn in staat om aan de hand van nauwkeurige zoekprotocollen en geavanceerde apparatuur bewijsmateriaal te vinden ten behoeve van de recherche. De Defensie Duikgroep doet hetzelfde, alleen dan onder water. Zij wordt geregeld ingezet voor het zoeken naar wapens of stoffelijke overschotten. De military trackers van het Korps Mariniers zijn spoorzoekers, die in het 'open veld' en in bosrijke omgevingen sporen van voortvluchtigen of vermisten kunnen aantreffen en interpreteren. Zij werden bijvoorbeeld ingezet bij de vermissingszaken Anne Faber in 2017 en de broertjes Ruben en Julian in 2013. Inmiddels heeft de Politie Eenheid Rotterdam twee eigen 'politie trackers', die op verzoek landelijk opereren en vaak samenwerken met de mariniers. 'Observeren' en 'analyseren' vinden we terug bij de verkenningseenheid JISTARC, die eigen observanten en analisten heeft en bijvoorbeeld heeft geholpen in de zaak rond de 'valkuilengraver' in het Limburgse Helden in 2009 en de diefstal van zitgrasmaaiers enkele jaren terug in het oosten van het land. Ook binnen de categorie 'observeren' en 'analyseren' valt het CMI Commando. Dat heeft de Amsterdamse politie enkele jaren terug geholpen met het gebiedswerk in multiculturele wijken op basis van methodieken en technieken die zijn ontwikkeld tijdens uitzendingen naar onder meer Afghanistan (Dijkstra 2015). 
Een derde en laatste belangrijk verschil tussen heden en verleden betreft de herwaardering door het bevoegd gezag van de militaire bijstand aan de politie. Als gevolg van het gewelddadige optreden van militairen bij onlusten in de negentiende eeuw en de eerste helft van de twintigste eeuw (zie het artikel van Smeets in dit themanummer) verminderde het draagvlak voor militaire bijstand bij het bevoegd gezag en in de samenleving sterk. Hierdoor was er lange tijd terughoudendheid om militairen te laten bijdragen aan politiewerk. Volgens Neuteboom (2017) kan deze herwaardering door het Openbaar Ministerie en burgemeesters worden verklaard door een heroriëntatie binnen de krijgsmacht als gevolg van de deelname aan talrijke buitenlandse missies in de afgelopen decennia. Daarbij verrichten militairen in toenemende mate 'politieachtig' werk (Neuteboom 2014). Te denken valt onder meer aan het zoeken en veiligstellen van bewijs voor internationale strafzaken, maar bijvoorbeeld ook aan het verrichten van crowd control, waarmee zij tijdens uitzending soms aan ordehandhaving doen. De internationale gemeenschap eist van militairen dat zij waar nodig tijdens missies kunnen optreden als constabulary force en daarmee dus wanneer nodig als een soort politiemacht de rechtsorde en de openbare orde handhaven. De krijgsmacht heeft daardoor tegenwoordig meer forensische expertise dan vroeger, die door defensie ook actief wordt aangeboden, en het Openbaar Ministerie en de burgemeester maken daar vervolgens graag gebruik van. Geïnterviewde officieren van justitie en burgemeesters geven aan dat de militairen vaak een 'andere manier van kijken en handelen' dan de politie inbrengen, die geregeld openingen biedt in strafzaken of bijvoorbeeld bij vermissingen. De herwaardering van de bijstand heeft verder te maken met de intensivering van de civiel-militaire samenwerking sinds de eeuwwisseling (Welten 2006) en - na de Koude Oorlog - een hernieuwde aandacht voor de bijdrage van de krijgsmacht aan de binnenlandse veiligheidssituatie (De Weger 2006). De binnenlandse veiligheidstaak van de krijgsmacht is, mede vanwege de terreurdreiging, (weer) belangrijk geworden.

\section{Waar het schuurt: bureaupolitieke twistpunten}

Volgens Neuteboom (2017) roept de bijdrage door de krijgsmacht aan de nationale veiligheid vandaag de dag weinig weerstand bij de bevol- 
king en/of politieke discussie op. Uit ons eigen onderzoek blijkt bovendien dat op het niveau van de dagelijkse uitvoering politiemensen en militairen elkaar goed weten te vinden. De zaak moet rond en de klus moet geklaard. Toch zijn er tussen politie en defensie geregeld onderhuidse verschillen van inzicht die het etiket bureaupolitiek verdienen. Daarbij gaat het zoals aangegeven om belangenconflicten tussen publieke organisaties.

In ons onderzoek Defensiehulp (Bervoets 2017) stuitten we op drie gevoelige belangenkwesties, die we hierna samenvatten. Soms gaat het om een soort grenstwisten in het perspectief van een - in de praktijk - onduidelijke grens tussen politie en krijgsmacht. Die vage grens is overigens van alle tijden, ondanks alle pogingen om beleidsmatig een scherp onderscheid te maken tussen beide instituties (De Weger 2006).

Een opvallende gevoeligheid bestaat eruit dat de politie de militaire bijstand soms ervaart als een brevet van onvermogen (Bervoets 2017, p. 91). Het bevoegd gezag vraagt hulp aan de krijgsmacht en dat voedt het beeld dat de politie op dat moment zelf een bepaalde capaciteit of expertise (even) niet in huis heeft. De politie laat echter niet graag taken door anderen uitvoeren die volgens haar onmiskenbaar bij de Nationale Politie horen. Zij geeft aan dat weliswaar soms extra capaciteit in de vorm van personeel nodig is om een klus te klaren, maar toegeven dat er mogelijk, al is het maar in de verte, sprake is van een kwaliteitsprobleem doet zij niet graag. Princen (2015) en ook sommige geïnterviewde politiemensen in ons onderzoek zijn er desalniettemin duidelijk over: de politie mist momenteel kwaliteit in de opsporing. Het probleem zou zich volgens de geïnterviewden vooral voordoen bij doorzoekingen van panden. De politie maakt bij zoekingen vaak gebruik van ad-hocteams met politiemensen voor wie zoeken geen specialiteit is, terwijl de krijgsmacht de beschikking heeft over 'advanced search'-teams. Een officier van justitie kiest dan geregeld voor het laatste, zeker als de zoeking wat ingewikkelder is. ${ }^{7}$

Een andere kwestie gaat om de vermeende profileringsdrang van defensie ten koste van de politie (Bervoets 2017, p. 108). Die drang wordt als concurrentie ervaren en als poging om met binnenlands optreden het eigen bestaansrecht te versterken. Met gretigheid worden volgens de politie diensten aangeboden die - soms met wat

7 Voor de echt complexe zoekingen - dus die veel verder gaan dan een routinematige huiszoeking - heeft de politie een eigen landelijk zoekteam. 
moeite - ook door de politie hadden kunnen worden verricht. Veel genoemd in de interviews is de zogeheten Catalogus Nationale Operaties, waarin defensie aangeeft wat ze civiele instanties allemaal te bieden heeft. Desgevraagd geven militaire commandanten aan dat zij het al druk genoeg hebben met uitzendingen naar het buitenland en niet zitten te wachten op meer bijstand aan de politie. Het beeld van de profileringsdrang wordt gevoed doordat defensie zich, zoals aangegeven, is gaan heroriënteren op haar taken. Daarbij is de zorg voor de binnenlandse veiligheid in belang toegenomen sinds de Defensienota van 2000. De politie heeft op haar beurt moeite met anderen die politietaken van haar trachten over te nemen. Bij dit bureaupolitieke twistpunt gaat het daarom vooral om het bewaken van de (kern)taken door de politie, door te voorkomen dat anderen deze taken gaan overnemen.

Een laatste bureaupolitiek twistpunt gaat over informele bijstandverlening (Bervoets 2017, p. 112). In de praktisch georiënteerde cultuur van uitvoerende politiemensen en militairen is het niet vreemd om elkaar gewoon rechtstreeks te bellen en om hulp en advies te vragen. In het verleden bleef dat niet beperkt tot een kort advies, maar werd er feitelijk, vanuit een 'can do'-mentaliteit, bijstand verleend aan de politie zonder dat die formeel - via het bevoegd gezag - was aangevraagd en goedgekeurd. Daarmee werd bijstand verleend zonder dat daar kosten voor in rekening werden gebracht. Defensie vindt dat een zeer onwenselijke situatie en geeft aan dat er tegenwoordig alles aan wordt gedaan om dit soort informele bijstand te voorkomen. Het bureaupolitieke twistpunt bestaat er dan uit dat de ene overheidsorganisatie niet - conform afspraken - wil betalen voor de bijstand door de andere overheidsorganisatie.

De bureaupolitieke twisten leiden tot meer dan gemor bij politie en defensie. Dat is te zien aan de merkwaardige beslissingen die soms in het politiewerk worden genomen, bijvoorbeeld bij vermissingen. Dan wordt pas als last resort (met als motto: 'we hebben er alles aan gedaan') gedacht aan de inzet van militairen die gespecialiseerd zijn in spoorzoeken en het terugvinden van personen en objecten. Inhoudelijk bekeken zou het voor de zaak beter zijn geweest om deze specialisten reeds vroeg in te zetten en de kans te vergroten dat een vermist persoon aan de hand van verse sporen (levend) wordt teruggevonden. Zowel het vermeende ‘brevet van onvermogen' van de politie als de profileringsdrang van defensie lijkt samen te hangen met de pluralise- 
ring van de politiefunctie. Pluralisering gaat zoals gezegd niet zonder - soms felle - bureaupolitiek. Zo heeft de politie geregeld ook moeite met de gemeentelijke handhavers, omdat de politie - nochtans een deel van de politiemensen - vindt dat deze handhavers taken overnemen die door de politie zelf zouden moeten worden vervuld. Denk aan het toezicht in de publieke ruimte. De beschreven bureaupolitieke twisten doen zich voor tegen de achtergrond van een toegenomen militaire bijstand. De vraag naar specialistische militaire bijstand zal volgens de politie afnemen als na de recente reorganisatie duidelijker is voor bevoegd gezag en politiemensen dat de politie zelf ook bepaalde diensten uitvoert die nu door defensie worden verricht. Het is dan overigens volgens sommige geïnterviewden wel de vraag in hoeverre de politie zelf allerlei kostbare expertise zou moeten ontwikkelen. De Nationale Politie hecht immers waarde aan generalisme boven specialisme bij de uitvoering van haar taken, wat onverlet laat dat zo nu en dan specialisten nodig zijn. Denk bijvoorbeeld aan financiële expertise en expertise op het gebied van cybercrime.

\section{Legergroene bijstand als pluralisering: niet zonder meer}

Neuteboom (2017) geeft aan dat de krijgsmacht (ook) een politiefunctie heeft: de binnenlandse inzet voor politiewerk door de Koninklijke Marechaussee en overige militairen. De legergroene inzet valt vanuit die optiek onder politiewerk en is dan een voorbeeld van plural policing. We hebben reden om deze kwestie desalniettemin met nuance te bekijken. In deze paragraaf gaan we na in hoeverre het etiket pluralisering past bij de ontwikkelingen zoals wij die waarnamen rond de legergroene bijstand. Dan blijkt de bijstand zoals bedoeld niet zonder meer ook pluralisering en heeft deze bijstand geen onbetwiste plek binnen de politiefunctie.

De vraag of bij legergroene bijstand sprake is van een aandeel in de brede politiefunctie en dus van pluralisering, was vroeger gemakkelijk met een 'ja' te beantwoorden. Met de bijstand bij openbareordehandhaving gaven militairen immers inhoud aan de politiefunctie.

De hedendaagse legergroene bijstand is echter niet gericht op toezicht of handhaving in de publieke ruimte, laat staan op het overnemen van toezichtstaken zoals bij gemeentelijke handhavers en private beveiligers. Ook gaat het bij de bijstand niet om 'new non-police providers', 
we weten immers dat de militaire bijstand geenszins nieuw is. De hedendaagse bijstand bij zoeken, observeren en analyseren lijkt desalniettemin op het inhoud geven aan de politiefunctie. Immers, zoeken, observeren en analyseren zijn kernactiviteiten binnen het reguliere politiewerk. De inhoud van de activiteiten beschouwd gaat het dus om politiewerk. De militairen haasten zich in onze interviews echter met te benadrukken dat zij de politie met de genoemde activiteiten ondersteunen en geen intentie hebben om politietaken over te nemen. Dat is volgens ons een bureaupolitieke reactie om de politie geen aanleiding te geven te denken dat de krijgsmacht zich zou willen profileren. De uitgevoerde activiteiten komen - hoe het ook zij - sterk overeen met politiewerk.

\section{Slot en nieuwe vragen}

De krijgsmacht is tegenwoordig onderdeel van een breder veiligheidsbeleid. Steeds meer wordt duidelijk dat de verschillende vormen van veiligheid intensief met elkaar samenhangen. (Muller e.a. 2017, p. 887). Om die reden is het belangrijk om de krijgsmacht meer te betrekken bij maatschappelijke veiligheid. Militairen kunnen meehelpen bij de aanpak van criminaliteit door kennis, mensen en middelen ter beschikking te stellen. De betekenis van de door ons bedoelde specialistische bijstand voor de politiefunctie is echter bepaald niet eenduidig. Specialistische bijstand is - zo gaven we reeds aan - niet automatisch hetzelfde als uitvoering geven aan de politietaak.

Desondanks kan de militaire bijstand door 'groene krijgsmachtonderdelen' onder plural policing worden geschaard, omdat het partijen betreft - anders dan de politie en Koninklijke Marechaussee - die hoe dan ook meehelpen met de veiligheid in de samenleving. Ook al is dat meehelpen bij de legergroene bijstand vaak specialistisch van aard en niet of minder gericht op sociale controle (waaronder toezicht). Pluralisering gaat verder niet zonder bureaupolitieke wrijving: de politie laat liever geen taken uitvoeren die zij naar eigen zeggen zelf kan uitvoeren of zou moeten uitvoeren. Ook bij militairen die bijstand verlenen, is sprake van bureaupolitiek. De belangenverschillen tussen politie en defensie hebben te maken met concurrentiegevoelens, de daarmee samenhangende vermeende profileringsdrang van organisaties 
en meningsverschillen ten aanzien van het financiële aspect van militaire bijstand.

Deze antwoorden roepen weer nieuwe vragen op voor de (nabije) toekomst. Het is de vraag hoe de waargenomen militaire bijstand en pluralisering van de politiefunctie zich verhouden tot de maatschappelijke opdracht van de politie (Terpstra 2010). Hiermee raken we meteen aan een klassiek dilemma in het politiebestel. De inhoud van de maatschappelijke opdracht is bepalend voor een nadruk op generalisme dan wel op specialisme. In ons onderzoek is waargenomen dat er van diverse kanten kracht op de politie wordt uitgeoefend om - bijvoorbeeld bij de aanpak van ondermijnende criminaliteit - meer werk te maken van specialisme. De vraag is dan: wat voor politie willen we? Dient het werk van de politie in het teken te staan van een continue wedloop met de zware criminaliteit, waarbij een stijgende vraag naar specialisme en dan wellicht dito bijstand onvermijdelijk is? Of moet de nadruk liggen op preventie en nabijheid, waarbij de generale taakstelling de aangewezen of toch in elk geval dominante strategie lijkt (zie ook Bayley 1994, die daar jaren geleden al vragen over stelde)? En wat voor krijgsmacht willen we? Een krijgsmacht die meer is dan een vangnet voor de politie? Een krijgsmacht die zich ontwikkelt richting een constabulary force, die dichter tegen politiewerk aankruipt, en daar ook zichtbaarder aan gaat bijdragen?

Vanuit de antwoorden op deze vragen moet worden bekeken of, hoe en met welke intensiteit, bijvoorbeeld met gezamenlijke ('joint') eenheden van politie en krijgsmacht kan worden gewerkt. Of dat de bijstand en de samenwerking alleen incidenteel plaatshebben waar noodzakelijk. Maar dat zijn toch vooral politieke vragen en geen vragen die zijn voorbehouden aan de wetenschap. Wel kan de wetenschap scenario's aandragen en uitwerken die zijn terug te voeren op strikt onderscheid ('separation'), samenwerking ('cooperation'), of zelfs het geheel opgaan in één enkele veiligheidsorganisatie ('merge') (Easton \& Moelker 2010). 


\section{Literatuur}

\section{Bayley 1994}

D. Bayley, Police for the future, Oxford: Oxford University Press 1994.

\section{Van den Berg e.a. 2012}

E. van den Berg, C. Hermans \&

J. Quast, Politiefunctie in perspectief: instrumenten voor toekomstgericht denken over de maatschappelijke functie van de politie, Den Haag: Ministerie van Veiligheid en Justitie 2012.

\section{Bervoets 2013}

E. Bervoets, Gemeentelijk blauw: het dagelijks werk van gemeentelijke handhavers in beeld, Apeldoorn: Politie en Wetenschap 2013.

\section{Bervoets 2015}

E. Bervoets, 'De straat op. Frontlijnwerkers bij straatoverlast', Cahiers Politiestudies (34) 2015, afl. 1, p. 69-81.

\section{Bervoets 2017}

E. Bervoets, Defensiehulp. Legergroene bijstand aan de politie bij handhaving van de rechtsorde, Apeldoorn: Politie en Wetenschap 2017.

\section{Bervoets \& Eijgenraam 2014}

E. Bervoets \& S. Eijgenraam, Privaat blauw: portiers, evenementbeveiligers en voetbalstewards op risicovolle locaties en tijdens risicovolle momenten, Apeldoorn: Politie en Wetenschap 2014.

\section{Bervoets \& Rovers 2016}

E. Bervoets \& B. Rovers, Wat vindt het publiek van gemeentelijke handhavers? Onderzoek naar het imago van gemeentelijke handhavers in vijf gemeenten, Amersfoort: Bureau Bervoets 2016.

\section{Bervoets e.a. 2016}

E. Bervoets, T. van Ham \& H. Ferwerda, Samen signaleren: burgerparticipatie bij sociale veiligheid, Den Haag: Platform31 2016.

\section{Brodeur \& Shearing 2005}

J.P. Brodeur \& C. Shearing, 'Configuring security and justice', European Journal of Criminology, (4) 2005, afl. 2, p. 371-406.

\section{Cachet 1990}

A. Cachet, Politie en sociale controle: over het effect van politieoptreden. Een vergelijkend onderzoek naar verkeersdelicten, gezinsgeweld en drugsgebruik, Arnhem: Gouda Quint 1990.

\section{Crawford 2007}

A. Crawford, 'Plural policing in the UK: Policing beyond the police', in: T. Newburn (red.), Handbook of policing, Londen: Routledge 2007.

\section{Devroe 2015}

E. Devroe, 'Bringing politics back into the study of policing', Policing and Society (25) 2015, afl. 4, p. 3-22. 


\section{Devroe \& Terpstra 2015}

E. Devroe \& J. Terpstra, 'Plural policing in Western Europe: A comparison', European Journal of Policing Studies (2) 2015, afl. 3, p. 235-244.

\section{Dijkstra 2015}

C. Dijkstra (red.), Anders kijken. Van probleemgericht sturen naar contextgericht beïnvloeden, Amsterdam: Politie Eenheid Amsterdam 2015.

\section{Easton \& Moelker 2010}

M. Easton \& R. Moelker, 'Police and military. Two worlds apart?', in: M. Easton, R. Moelker, M. den Boer \& T. Vander Beken, Blurring military and police roles, Den Haag: Eleven International Publishing 2010, p.11-31.

\section{Fijnaut 2007}

C. Fijnaut, De geschiedenis van de Nederlandse politie, Amsterdam: Boom 2007.

\section{Forster 2006}

A. Forster, Armed forces and society in Europe, Hampshire: Palgrave Macmillan 2006.

\section{Garland 2001}

D. Garland, The culture of control: Crime and social order in contemporary society, Chicago: University of Chicago Press 2001.

\section{Jones \& Newburn 2006}

T. Jones \& T. Newburn, Plural policing: A comparative perspective, Londen: Routledge 2006.

\section{Loader 2000}

I. Loader, 'Plural policing and democratic governance', Social and Legal Studies (9) 2000, afl. 3, p. 325-345.

\section{Muller e.a. 2017}

E. Muller, H. Bosch, I. de Jong \& P. Ducheine, Krijgsmacht: studies over de organisatie en het optreden, Deventer: Wolters Kluwer 2017.

\section{Neuteboom 2017}

P.C.J. Neuteboom, 'De politiefunctie van de krijgsmacht', in: E. Muller, H. Bosch, I. de Jong \& P. Ducheine (red.), Krijgsmacht: studies over de organisatie en het optreden, Deventer: Wolters Kluwer 2017, p. 201-224.

\section{O’Neill \& Fyfe 2017}

M. O’Neill \& N. Fyfe, 'Plural policing in Europe: Relationships and governance in contemporary security systems', Policing and Society (27) 2017, p. 1-5.

\section{Princen 2015}

M. Princen, De gekooide recherche, Amsterdam: Prometheus Bert Bakker 2015.

\section{Reiner 2010}

R. Reiner, Politics of the police, Oxford: Oxford University Press 2010. 


\section{Rosenthal e.a. 1994}

U. Rosenthal, P. 't Hart \& H.G. Geveke, 'Beslissen in een competitief overheidsbestel: bureaupolitiek en bureaupolitisme nader beschouwd', Acta Politica (29) 1994, afl. 3, p. 309-334.

\section{Smeets 1997}

J. Smeets, Het Korps Politietroepen (1919-1940): de politie-militair als steunpilaar van het wettig gezag, Soest: Klomp Grafische Bedrijven 1997.

\section{Van Steden 2007}

R. van Steden, Privatizing policing: Describing and explaining the growth of private security, Den Haag: Boom Juridische uitgevers 2007.

\section{Van Stokkom \& Bervoets 2017}

B. van Stokkom \& E. Bervoets, Tussen buurtwacht en weerkorps: zijn (digitale) burgerpatrouilles toelaatbaar? (Cahiers Politiestudies), Apeldoorn: Maklu 2017.

\section{Terpstra 2010}

J. Terpstra, De maatschappelijke opdracht van de politie. Over identiteit en kernelementen (oratie Nijmegen), Den Haag: Boom Juridische uitgevers 2010.

\section{Terpstra e.a. 2013}

J. Terpstra, B. van Stokkom \& R. Spreeuwers, Who patrols the streets? An international comparative study of plural policing, Den Haag: Eleven International Publishing 2013.

\section{Timmer 2011}

J. Timmer, 'De politiepet te boven: de meerwaarde van speciale eenheden voor de Nederlandse politietaak', in: A.C. Spapens, M.S. Groenhuijsen \& T. Kooijmans (red.), Universalis. Liber amicorum Cyrille Fijnaut, Antwerpen: Intersentia 2011.

\section{Van der Wal 2002}

R. van der Wal, Militaire bijstand bij de handhaving en het herstel van de openbare orde 1840-1920 (diss. Utrecht), 2002.

\section{De Weger 2006}

M. de Weger, De binnenlandse veiligheidstaken van de Nederlandse krijgsmacht, Assen: Van Gorcum 2006.

\section{Welten 2006}

B.J.A.M. Welten, 'Niet alleen in geval van nood', Militaire Spectator (175) 2006, afl. 11, 490-499.

\section{De Wijk \& Toxopeus 2005}

R. de Wijk \& R. Toxopeus, 'Hoe binnenlandse en buitenlandse veiligheid verweven zijn', Militaire Spectator (59) 2005, afl. 7/8, p. 421-425. 